\title{
Profit Malmquist Index and Its Global Form in the Presence of the Negative Data in DEA
}

\author{
Ghasem Tohidi, ${ }^{1}$ Shabnam Razavyan, ${ }^{2}$ and Simin Tohidnia ${ }^{1}$ \\ ${ }^{1}$ Department of Mathematics, Islamic Azad University, Central Tehran Branch, Tehran, Iran \\ ${ }^{2}$ Department of Mathematics, Islamic Azad University, South Tehran Branch, Tehran, Iran \\ Correspondence should be addressed to Ghasem Tohidi; ghatohidi@yahoo.com
}

Received 8 January 2014; Accepted 7 August 2014; Published 31 August 2014

Academic Editor: Farhad Hosseinzadeh Lotfi

Copyright (c) 2014 Ghasem Tohidi et al. This is an open access article distributed under the Creative Commons Attribution License, which permits unrestricted use, distribution, and reproduction in any medium, provided the original work is properly cited.

\begin{abstract}
This paper first introduces the allocative and profit efficiency in the presence of the negative data and then presents a new circular index to measure the productivity change of decision making units (DMUs) for the case that the dataset contains the inputs and/or outputs with the negative values in data envelopment analysis (DEA). The proposed index is decomposed into four components in the two stages. The range directional model (RDM) and the proposed efficiencies are used to compute the proposed index and its components. The interpretations of the components are presented. Finally, a numerical example is organized to illustrate the proposed index and its components at three successive periods of time.
\end{abstract}

\section{Introduction}

The Malmquist productivity index which measures the productivity change over time was introduced by Caves et al. [1]. Fare et al. [2] developed the Malmquist productivity index that was based on data envelopment analysis (DEA). The Malmquist index can be applied in many fields $[3,4]$. By using Malmquist index, the productivity growth can be decomposed into the efficiency change and technical change components. The second component measures the shift in the technology frontier.

Pastor and Lovell [5] suggested the global Malmquist productivity index that is circular and can be decomposed into the circular components. The global index and the metaMalmquist index developed in Portela and Thanassoulis [6]. In addition, Hosseinzadeh Lotfi et al. developed the new ideas about Malmquist index in $[7,8]$.

Maniadakis and Thanassoulis [9] assumed the input cost vector is known and suggested the cost Malmquist index. Tohidi et al. [10] extended the cost Malmquist index into the profit Malmquist index that is used when the input cost and the output price vector are available. Then, Tohidi and Razavyan [11] proposed the global profit Malmquist index. The cost Malmquist index was also developed in Tohidi et al. [12] and is called the global cost Malmquist productivity index.

Sometimes in the process of production negative inputs and/or outputs may occur. For example, DMUs may generate undesirable outputs. In such a case, negative values can be considered for these undesirable outputs. Instances of systems with negative inputs and/or outputs are explained in $[13,14]$. The traditional DEA models can be applied to compute the Malmquist index with the nonnegative data. They cannot deal with the negative data. Portela et al. [15] presented an approach named the range directional model $(\mathrm{RDM})$ and solved this problem. They calculated the metaMalmquist index using the RDM model in Portela and Thanassoulis [16].

To investigate the productivity change of DMUs with the negative data, this paper defines the profit and allocative efficiency and introduces an index to measure the productivity changes of DMUs when some inputs and/or outputs are negative and the costs of inputs and the prices of outputs are available. Then, the proposed index is decomposed into some components in the two stages. The range directional model $(\mathrm{RDM})$ and the proposed efficiencies are used to compute the proposed index and its components. 
The current paper unfolds as follows. Section 2 describes the RDM. In Section 3 the global Malmquist productivity index is expressed. Section 4 defines the profit and the allocative efficiency for the DMUs with some negative inputs and outputs and then suggests a new index. The decomposition and the theorem of circularity property of the proposed index and its components are presented in Section 5. Section 6 prepares some DEA models to compute the proposed index and its components. Section 7 provides a numerical example. Section 8 concludes.

\section{The Range Directional Model}

Portela et al. [15] introduced the RDM to compare DMUs under the negative data. Assume that, in time period $t(t=$ $1, \ldots, T)$ and $j$ th unit $(j=1, \ldots, n)$ consumes an input vector $x_{j}^{t}=\left(x_{1 j}^{t}, x_{2 j}^{t}, \ldots, x_{m j}^{t}\right)$ to produce an output vector $y_{j}^{t}=\left(y_{1 j}^{t}, y_{2 j}^{t}, \ldots, y_{s j}^{t}\right)$. We consider an ideal point (IP) for the time period $t$ with the minimum inputs and the maximum outputs observed in this time period, where for each input $i(i=1, \ldots, m)$ and $\operatorname{IP}_{i}$ is as $\min _{j}\left\{x_{i j}^{t}\right\}$ and for each output $r(r=1, \ldots, s)$ throughout $\operatorname{IP}_{r}$ is as $\max _{j}\left\{y_{r j}^{t}\right\}$ and the directional vector is as $\left(g_{x}, g_{y}\right)=\left(g_{x_{1}^{t}}, \ldots, g_{x_{m}^{t}}, g_{y_{1}^{t}}, \ldots, g_{y_{s}^{t}}\right)$. In the RDM this directional vector for $\mathrm{DMU}_{k}$ in time period $t$ is as $g_{x_{i k}^{t}}=R_{x_{i k}^{t}}=x_{i k}^{t}-\min _{j}\left\{x_{i j}^{t}\right\} ; i=1, \ldots, m$ and $g_{y_{r k}^{t}}=R_{y_{r k}^{t}}=\max _{j}\left\{y_{r j}^{t}\right\}-y_{r k}^{t} ; r=1, \ldots, s$ that reflects the ranges of possible improvement for this DMU. The RDM for $\mathrm{DMU}_{k}$ in time period $t$ for the case of the VRS technology is as follows (Portela et al., 2004):

$$
\begin{aligned}
\beta_{k}^{*}=\max & \beta_{k} \\
\text { s.t. } \quad & \sum_{j=1}^{n} \lambda_{j} x_{i j}^{t} \leq x_{i k}^{t}-\beta_{k} R_{x_{i k}^{t}}, \quad i=1, \ldots, m, \\
& \sum_{j=1}^{n} \lambda_{j} y_{r j}^{t} \geq y_{r k}^{t}+\beta_{k} R_{y_{r k}^{t}}, \quad r=1, \ldots, s, \\
& \sum_{j=1}^{n} \lambda_{j}=1, \\
& \lambda_{j} \geq 0, \quad j=1, \ldots, n .
\end{aligned}
$$

The value of $\beta_{k}^{*}$ in model (1) is an inefficiency measure and the RDM efficiency measure of unit $k$ is $\operatorname{RDM}^{t}\left(x_{k}^{t}, y_{k}^{t}, R_{x_{k}^{t}}, R_{y_{k}^{t}}\right)=1-\beta_{k}^{*}$ that is defined as $\left(x_{i k}^{t *}-\min _{j}\left\{x_{i j}^{t}\right\}\right) /\left(x_{i k}^{t}-\min _{j}\left\{x_{i j}^{t}\right\}\right)$ if at the optimal solution to model (1) a binding constraint corresponds to input $i$ or $\left(\max _{j}\left\{y_{r j}^{t}\right\}-y_{r k}^{t *}\right) /\left(\max _{j}\left\{y_{r j}^{t}\right\}-y_{r k}^{t}\right)$ if a binding constraint corresponds to output $r . x_{i k}^{t}{ }^{*}$ and $y_{r k}^{t}{ }^{*}$ are the target inputs and target outputs in time $t$, respectively. It is clear that the upper bound of $1-\beta_{k}^{*}$ is 1 .

\section{The Global Profit Malmquist Productivity Index}

The global profit Malmquist index $\left(\mathrm{PM}^{G}\right)$ is applied to measure the productivity changes of DMUs when the input costs and output prices are available. Assume that, in time period $t,(t=1, \ldots, T)$, the input cost vector is $c^{t} \in R_{+}^{m}$ and the output price vector is $p^{t} \in R_{+}^{s}$; by using these vectors the common input cost vector $c^{G} \in R_{+}^{m}$ and the common output price vector $p^{G} \in R_{+}^{s}$ can be defined, respectively, as $c^{G}=\sum_{j=1}^{T} \lambda_{j} c^{j}, \sum_{j=1}^{T} \lambda_{j}=1, \lambda_{j} \geq 0$, and $p^{G}=$ $\sum_{j=1}^{T} \mu_{j} p^{j}, \sum_{j=1}^{T} \mu_{j}=1, \mu_{j} \geq 0$, where the weights $\lambda_{j}$ and $\mu_{j}(j=1, \ldots, T)$ are the decision-makers' preferences over $c^{j}$ and $p^{j}(j=1, \ldots, T)$, respectively [12].

This paper uses the definition of profit [13] to compute the global profit and the observed profit of $\mathrm{DMU}_{k}$ with the negative data. The observed profit of $\mathrm{DMU}_{j}$ under the cost and price vectors of time period $t$ can be calculated as $\operatorname{OP}^{t}\left(x_{j}^{t}, y_{j}^{t}\right)=p^{t} y_{j}^{t}-c^{t} x_{j}^{t}$ and the maximum profit of time $t$ under the price vector of this time is defined as $\operatorname{MP}^{t}\left(x, y, c^{t}, p^{t}\right)=\max \left\{p^{t} y-c^{t} x:(x, y) \in T^{t}, c^{t}>0, p^{t}>0\right\}$. The set of activities $(x, y) \in T^{t}$ which corresponds to the scalar $\operatorname{MP}^{t}\left(x, y, c^{t}, p^{t}\right)$ defines the profit boundary of time $t$ as $\overline{\mathrm{MP}}^{t}=\left\{(x, y): p^{t} y-c^{t} x=\mathrm{MP}^{t}\left(x, y, c^{t}, p^{t}\right)\right\}$. In this case the $\mathrm{PM}^{G}$ index for the DMUs with the nonnegative data is defined as follows:

$$
\mathrm{PM}^{G}=\frac{\mathrm{MP}^{G}\left(x^{t+1}, y^{t+1}, c^{G}, p^{G}\right) / \mathrm{OP}^{G}\left(x^{t+1}, y^{t+1}\right)}{\operatorname{MP}^{G}\left(x^{t}, y^{t}, c^{G}, p^{G}\right) / \mathrm{OP}^{G}\left(x^{t}, y^{t}\right)},
$$

where $\operatorname{MP}^{G}\left(x^{t}, y^{t}, c^{G}, p^{G}\right)=\max \left\{p^{G} y-c^{G} x:(x, y) \epsilon\right.$ $\left.T^{G}, c^{G}>0, p^{G}>0\right\}$ and $T^{G}=\operatorname{conv}\left\{T^{1} \cup \cdots \cup T^{T}\right\}$ is the global production technology [5]. The term $\mathrm{OP}^{G}\left(x^{t}, y^{t}\right)=p^{G} y^{t}-$ $c^{G} x^{t}$ is the observed profit of $\left(x^{t}, y^{t}\right)$ under the common price vectors $c^{G}$ and $p^{G}$. The ratio $\mathrm{MP}^{G}\left(x^{t}, y^{t}, c^{G}, p^{G}\right) / \mathrm{OP}^{G}\left(x^{t}, y^{t}\right)$ in the denominator of $\mathrm{PM}^{G}$ is the reciprocal to measure of the profit efficiency introduced in Cooper et al. [13] for $\left(x^{t}, y^{t}\right)$ under the common price vectors. This ratio measures the distance between the observed profit $\mathrm{OP}^{G}\left(x^{t}, y^{t}\right)$ and the common profit boundary and will have a minimum value of 1 . A value greater than 1 of $\mathrm{PM}^{G}$ index indicates the productivity regress and a value less than 1 implies the productivity progress between $t$ and $t+1$. A value of 1 indicates that the productivity remains unchanged. Because of the limitations of the DEA models with the negative inputs and outputs $[17,18]$, we cannot investigate the productivity change of DMUs with the negative data by using tradition Malmquist indices. To this end, the next section proposes an appropriate global profit Malmquist index when some inputs or/and outputs are negative. 


\section{The Global Profit Malmquist Index with the Negative Data}

In this section we assume that there are some negative inputs and/or negative outputs and evaluate the productivity changes of DMUs by using the $\mathrm{PM}^{G}$ index under the VRS technology. We denote the profit of the ideal point of time period $t$ by $\mathrm{IP}^{t}$ that the superscript $t$ on $\mathrm{IP}^{t}$ indicates the profit is computed under the cost and the price vectors of time $t$. By using the definition of the profit, we will have

$$
\mathrm{OP}^{t}\left(x^{t}, y^{t}\right) \leq \mathrm{MP}^{t}\left(x^{t}, y^{t}, c^{t}, p^{t}\right) \leq \mathrm{IP}^{t} .
$$

Now we define the profit and allocative efficiency of a DMU with the negative data.

Definition 1. The measure of the profit efficiency for $\left(x^{t}, y^{t}\right)$ under the price vectors of time $t$ is as

$$
\mathrm{PE}^{t}\left(y^{t}, x^{t}, c^{G}, p^{G}\right)=\frac{\mathrm{MP}^{t}\left(x^{t}, y^{t}, c^{t}, p^{t}\right)-\mathrm{IP}^{t}}{\mathrm{OP}^{t}\left(x^{t}, y^{t}\right)-\mathrm{IP}^{t}} .
$$

By using (3) it is clear that the value of $\operatorname{PE}^{t}\left(y^{t}, x^{t}\right.$, $\left.c^{G}, p^{G}\right)$ is equal to or less than one. As the profit efficiency is less than 1 it may be because production takes place at the wrong input and/or output mix in light of the input costs and the output prices; this is captured by using the measure of the allocative efficiency which is defined as follows.

Definition 2. Let $\left(x^{t *}, y^{t *}\right)$ be the target DMU of $\left(x^{t}, y^{t}\right)$ in time period $t$ using RDM. The allocative efficiency of $\left(x^{t}, y^{t}\right)$ can be defined as follows:

$$
\begin{aligned}
\operatorname{AE}^{t}\left(y^{t}, x^{t}, w^{t}\right) \\
=\frac{\operatorname{MP}^{t}\left(x^{t}, y^{t}, c^{t}, p^{t}\right)-\mathrm{IP}^{t}}{\mathrm{OP}^{t}\left(x^{t^{*}}, y^{t^{*}}\right)-\mathrm{IP}^{t}} \\
=\frac{\mathrm{MP}^{t}\left(x^{t}, y^{t}, c^{t}, p^{t}\right)-\mathrm{IP}^{t}}{\left(\mathrm{OP}^{t}\left(x^{t}, y^{t}\right)-\mathrm{IP}^{t}\right) \mathrm{RDM}^{t}\left(x_{k}^{t}, y_{k}^{t}, R_{x_{k}^{t}}, R_{y_{k}^{t}}\right)} \\
=\frac{\operatorname{PE}^{t}\left(y^{t}, x^{t}, c^{G}, p^{G}\right)}{\operatorname{RDM}^{t}\left(x_{k}^{t}, y_{k}^{t}, R_{x_{k}^{t}}, R_{y_{k}^{t}}\right)} .
\end{aligned}
$$

If profit efficiency is less than 1 and it is because production is based on excessive input or shortage output usage, we can capture it by using the RDM efficiency measure that was denoted by $\operatorname{RDM}^{t}\left(x_{k}^{t}, y_{k}^{t}, R_{x_{k}^{t}}, R_{y_{k}^{t}}\right)$.

To define the $\mathrm{PM}^{G}$ index under the VRS technology in the presence of the negative datawe first consider a global ideal point (GIP) defined over the global technology that, for input $i(i=1, \ldots, m)$, and output $r(r=1, \ldots, s)$, is as $\mathrm{GIP}_{i}=$ $\min _{t}\left\{\min _{j}\left\{x_{i j}^{t}\right\}\right\}$ and $\mathrm{GIP}_{r}=\max _{t}\left\{\max _{j}\left\{y_{r j}^{t}\right\}\right\}$, respectively. This ideal point is used for computing the range $R^{\mathrm{GF}}=$ $\left(R_{x^{t}}^{\mathrm{GF}}, R_{y^{t}}^{\mathrm{GF}}\right)$ for $\mathrm{DMU}_{k}$ observed in time $t$. The $i$ th component of $R_{x^{t}}^{\mathrm{GF}}$ is $R_{x_{i k}^{t}}^{\mathrm{GF}}=x_{i k}^{t}-\min _{t}\left\{\min _{j}\left\{x_{i j}^{t}\right\}\right\}, i=1, \ldots, m$, and $r$ th component of $R_{y^{t}}^{\mathrm{GF}}$ is $R_{y_{r k}^{t}}^{\mathrm{GF}}=\max _{t}\left\{\max _{j}\left\{y_{r j}^{t}\right\}\right\}-y_{r j}^{t}, r=$
$1, \ldots, s$. Now we define the $\mathrm{PM}^{G}$ index in the presence of the negative data as follows:

$$
\begin{aligned}
\mathrm{PM}^{G}= & \left(\frac{\left(\mathrm{MP}^{G}\left(x^{t+1}, y^{t+1}, c^{G}, p^{G}\right)-\mathrm{GIP}^{G}\right)}{\left(\mathrm{OP}^{G}\left(x^{t+1}, y^{t+1}\right)-\mathrm{GIP}^{G}\right)}\right) \\
& \times\left(\frac{\left(\mathrm{MP}^{G}\left(x^{t}, y^{t}, c^{G}, p^{G}\right)-\mathrm{GIP}^{G}\right)}{\left(\mathrm{OP}^{G}\left(x^{t}, y^{t}\right)-\mathrm{GIP}^{G}\right)}\right)^{-1},
\end{aligned}
$$

where $\operatorname{GIP}^{G}$ is the profit of the global ideal point and the superscript $G$ indicates that the profit of this point is computed under the common price vectors $c^{G}$ and $p^{G}$. The ratio $\left(\mathrm{MP}^{G}\left(x^{t}, y^{t}, c^{G}, p^{G}\right)-\mathrm{GIP}^{G}\right) /\left(\mathrm{OP}^{G}\left(x^{t}, y^{t}\right)-\mathrm{GIP}^{G}\right)$ is the profit efficiency defined in Definition 1 under the common cost and price vectors. When the $\mathrm{PM}^{G}$ index has the value greater than 1 , it means that the productivity of unit $k$ has improved from the time $t$ to $t+1$. The productivity has declined when the value of the $\mathrm{PM}^{G}$ index is below 1 and remains unchanged if $\mathrm{PM}^{G}=1$. The $\mathrm{PM}^{G}$ index is circular and it can be decomposed into four circular components as shown in the next section.

\section{Decomposition of the $\mathrm{PM}^{G}$ Index}

In the first stage the $\mathrm{PM}^{G}$ index is decomposed into two $\mathrm{PEC}^{G}$ and $\mathrm{PTC}^{G}$ as follows:

$$
\begin{aligned}
\mathrm{PM}^{G}= & \left(\frac{\left(\mathrm{MP}^{t+1}\left(x^{t+1}, y^{t+1}, c^{t+1}, p^{t+1}\right)-\mathrm{GIP}^{t+1}\right)}{\left(\mathrm{OP}^{t+1}\left(x^{t+1}, y^{t+1}\right)-\mathrm{GIP}^{t+1}\right)}\right) \\
\times & \left(\frac{\left(\mathrm{MP}^{t}\left(x^{t}, y^{t}, c^{t}, p^{t}\right)-\mathrm{GIP}^{t}\right)}{\left(\mathrm{OP}^{t}\left(x^{t}, y^{t}\right)-\mathrm{GIP}^{t}\right)}\right)^{-1} \\
\times & {\left[\left(\frac{\left(\mathrm{MP}^{G}\left(x^{t+1}, y^{t+1}, c^{G}, p^{G}\right)-\mathrm{GIP}^{G}\right)}{\left(\mathrm{OP}^{G}\left(x^{t+1}, y^{t+1}\right)-\mathrm{GIP}^{G}\right)}\right)\right.} \\
& \times\left(\frac{\left(\mathrm{MP}^{t+1}\left(x^{t+1}, y^{t+1}, c^{t+1}, p^{t+1}\right)-\mathrm{GIP}^{t+1}\right)}{\left(\mathrm{OP}^{t+1}\left(x^{t+1}, y^{t+1}\right)-\mathrm{GIP}^{t+1}\right)}\right) \\
& \times\left(\frac{\left(\mathrm{MP}^{t}\left(x^{t}, y^{t}, c^{t}, p^{t}\right)-\mathrm{GIP}^{t}\right)}{\left(\mathrm{OP}^{t}\left(x^{t}, y^{t}\right)-\mathrm{GIP}^{t}\right)}\right) \\
& \left.\times\left(\frac{\left(\mathrm{MP}^{G}\left(x^{t}, y^{t}, c^{G}, p^{G}\right)-\mathrm{GIP}^{G}\right)}{\left(\mathrm{OP}^{G}\left(x^{t}, y^{t}\right)-\mathrm{GIP}^{G}\right)}\right)^{-1}\right]
\end{aligned}
$$

The term outside the brackets in the right-hand side of (7) represents the profit efficiency change $\left(\mathrm{PEC}^{G}\right)$ component of the unit under evaluation from $t$ to $t+1$ and the term inside the brackets provides the profit frontier shift (the technical change) between the periods $t$ and $t+1$ under the VRS production technologies oftwo times $t$ and $t+1\left(\mathrm{PTC}^{G}\right)$. 
The $\mathrm{PEC}^{G}$ and $\mathrm{PTC}^{G}$ components of the $\mathrm{PM}^{G}$ index can themselves be decomposed.
The Decomposition of the PEC ${ }^{G}$. The $\mathrm{PEC}^{G}$ component can be decomposed into two components as follows:

$$
\begin{aligned}
\mathrm{PEC}^{G}= & \frac{\left(\mathrm{MP}^{t+1}\left(x^{t+1}, y^{t+1}, c^{t+1}, p^{t+1}\right)-\mathrm{GIP}^{t+1}\right) /\left(\mathrm{OP}^{t+1}\left(x^{t+1}, y^{t+1}\right)-\mathrm{GIP}^{t+1}\right) \mathrm{RDM}^{t+1}\left(x^{t+1}, y^{t+1}, R_{x^{t+1}}^{\mathrm{GF}}, R_{y^{t+1}}^{\mathrm{GF}}\right)}{\left(\mathrm{MP}^{t}\left(x^{t}, y^{t}, c^{t}, p^{t}\right)-\mathrm{GIP}^{t}\right) /\left(\mathrm{OP}^{t}\left(x^{t}, y^{t}\right)-\mathrm{GIP}^{t}\right) \mathrm{RDM}^{t}\left(x^{t}, y^{t}, R_{x^{t}}^{\mathrm{GF}}, R_{y^{t}}^{\mathrm{GF}}\right)} \\
& \times \frac{\mathrm{RDM}^{t+1}\left(x^{t+1}, y^{t+1}, R_{x^{t+1}}^{\mathrm{GF}}, R_{y^{t+1}}^{\mathrm{GF}}\right)}{\operatorname{RDM}^{t}\left(x^{t}, y^{t}, R_{x^{t}}^{\mathrm{GF}}, R_{y^{t}}^{\mathrm{GF}}\right)},
\end{aligned}
$$

where $\mathrm{GIP}^{t}$ and $\mathrm{GIP}^{t+1}$ are the profit of the global point under the costs and prices of the periods $t$ and $t+1$, respectively. The first ratio in the right-hand side of (8) is the allocative efficiency change $\left(\mathrm{AEC}^{G}\right)$ components of the $\mathrm{PM}^{G}$ index; and the second ratio is the RDM within-period-efficiency change
$\left(\mathrm{REC}^{G}\right)$ of the unit that is under evaluation from $t$ to $t+1$; the RDM within-period-efficiency change was introduced by Portela et al. [15].

The Decomposition of $\mathrm{PTC}^{G}$. We can decompose the $\mathrm{PTC}^{G}$ into two components as follows:

$$
\begin{aligned}
\mathrm{PTC}^{G}= & \frac{\mathrm{RDM}^{G}\left(x^{t+1}, y^{t+1}, R_{x^{t+1}}^{\mathrm{GF}}, R_{y^{t+1}}^{\mathrm{GF}}\right) \mathrm{RDM}^{t}\left(x^{t}, y^{t}, R_{x^{t}}^{\mathrm{GF}}, R_{y^{t}}^{\mathrm{GF}}\right)}{\mathrm{RDM}^{t+1}\left(x^{t+1}, y^{t+1}, R_{x^{t+1}}^{\mathrm{GF}}, R_{y^{t+1}}^{\mathrm{GF}}\right) \mathrm{RDM}^{G}\left(x^{t}, y^{t}, R_{x^{t}}^{\mathrm{GF}}, R_{y^{t}}^{\mathrm{GF}}\right)} \\
\times & \left(\left(\frac{\mathrm{MP}^{G}\left(x^{t+1}, y^{t+1}, c^{G}, p^{G}\right)-\mathrm{GIP}^{G}}{\left(\mathrm{OP}^{G}\left(x^{t+1}, y^{t+1}\right)-\mathrm{GIP}^{G}\right) \mathrm{RDM}^{G}\left(x^{t+1}, y^{t+1}, R_{x^{\mathrm{GF}}}^{\mathrm{GF}}, R_{y^{t+1}}^{\mathrm{GF}}\right)}\right)\right. \\
& \left.\times\left(\frac{\mathrm{MP}^{t+1}\left(x^{t+1}, y^{t+1}, c^{t+1}, p^{t+1}\right)-\mathrm{GIP}^{t+1}}{\left(\mathrm{OP}^{t+1}\left(x^{t+1}, y^{t+1}\right)-\mathrm{GIP}^{t+1}\right) \mathrm{RDM}^{t+1}\left(x^{t+1}, y^{t+1}, R_{x^{t+1}}^{\mathrm{GF}}, R_{y^{t+1}}^{\mathrm{GF}}\right)}\right)^{-1}\right) \\
& \times\left(\frac{\left(\mathrm{MP}^{t}\left(x^{t}, y^{t}, c^{t}, p^{t}\right)-\mathrm{GIP}^{t}\right)}{\left.\mathrm{GIP}^{t}\right) \mathrm{RDM}^{t}\left(x^{t}, y^{t}, R_{x^{t}}^{\mathrm{GF}}, R_{y^{t}}^{\mathrm{GF}}\right)}\right) \\
& \left.\left.\quad \times\left(\frac{\mathrm{MP}^{G}\left(x^{t}, y^{t}, c^{G}, p^{G}\right)-\mathrm{GIP}^{G}}{\left(\mathrm{OP}^{G}\left(x^{t}, y^{t}\right)-\mathrm{GIP}^{G}\right) \mathrm{RDM}^{G}\left(x^{t}, y^{t}, R_{x^{t}}^{\mathrm{GF}}, R_{y^{t}}^{\mathrm{GF}}\right)}\right)^{-1}\right)\right]
\end{aligned}
$$

The first term in the above decomposition measures the frontier shift between the VRS frontiers of times $t$ and $t+1$ and the technical change $\left(\mathrm{TC}^{G}\right)$, along the ray $\left(x_{j}^{t+1}, y_{j}^{t+1}\right)$ [16]. The second term is a residual price effect $\left(\mathrm{PE}^{G}\right)$ part. The numerical values of the components of the $\mathrm{PM}^{G}$ index obtained in this section are interpreted in the similar manner as the index itself; a value below 1 indicates regress, greater than 1 indicates progress, and 1 indicates that performance stayed constant.

5.1. The Circularity Property of $P M^{G}$ and All of Its Components. Circularity is a prominent property of the $\mathrm{PM}^{G}$ index and all of its components in the presence of the negative data. To show this property, the following theorem is stated.
Theorem 3. For every DMU $U_{j}(j=1, \ldots, n)$, in three successive periods,

(1) $P M_{t, t+2}^{G}=P M_{t, t+1}^{G} \times P M_{t+1, t+2}^{G}$ (the circularity of $P M^{G}$ ),

(2) $P E C_{t, t+2}^{G}=P E C_{t, t+1}^{G} \times P E C_{t+1, t+2}^{G}$ (the circularity of $\left.P E C^{G}\right)$,

(3) $P T C_{t, t+2}^{G}=P T C_{t, t+1}^{G} \times P T C_{t+1, t+2}^{G}$ (the circularity of $\left.P T C^{G}\right)$,

(4) $R E C_{t, t+2}^{G}=R E C_{t, t+1}^{G} \times R E C_{t+1, t+2}^{G}$ (the circularity of $\left.R E C^{G}\right)$,

(5) $A E C_{t, t+2}^{G}=A E C_{t, t+1}^{G} \times A E C_{t+1, t+2}^{G}$ (the circularity of $A E C^{G}$ ),

(6) $T C_{t, t+2}^{G}=T C_{t, t+1}^{G} \times T C_{t+1, t+2}^{G}$ (the circularity of $T C^{G}$ ),

(7) $P E_{t, t+2}^{G}=P E_{t, t+1}^{G} \times P E_{t+1, t+2}^{G}$ (the circularity of $P E^{G}$ ), 
where, for instance, $P M_{p, q}^{G}(p=t, t+1, q=t+1, t+2, p \neq q)$ is the profit Malmquist changes between periods $p$ and $q$ for $D M U_{j}$.

Proof. For instance, let $\mathrm{PM}_{p, q}^{G}$ be the profit Malmquist changes between periods $p$ and $q$ for $\mathrm{DMU}_{j}$. Therefore,

$$
\begin{aligned}
\mathrm{PM}_{t, t+1}^{G} \times \mathrm{PM}_{t+1, t+2}^{G} & \left(\left(\frac{\mathrm{MP}^{G}\left(x^{t+1}, y^{t+1}, c^{G}, p^{G}\right)-\mathrm{GIP}^{G}}{\mathrm{OP}^{G}\left(x^{t+1}, y^{t+1}\right)-\mathrm{GIP}^{G}}\right)\right. \\
& \left.\times\left(\frac{\mathrm{MP}^{G}\left(x^{t}, y^{t}, c^{G}, p^{G}\right)-\mathrm{GIP}^{G}}{\mathrm{OP}^{G}\left(x^{t}, y^{t}\right)-\mathrm{GIP}^{G}}\right)\right) \\
\times & \left(\left(\frac{\mathrm{MP}^{G}\left(x^{t+2}, y^{t+2}, c^{G}, p^{G}\right)-\mathrm{GIP}^{G}}{\mathrm{OP}^{G}\left(x^{t+2}, y^{t+2}\right)-\mathrm{GIP}^{G}}\right)\right. \\
& \times\left(\frac{\mathrm{MP}^{G}\left(x^{t+1}, y^{t+1}, c^{G}, p^{G}\right)-\mathrm{GIP}^{G}}{\mathrm{OP}^{G}\left(x^{t+1}, y^{t+1}\right)-\mathrm{GIP}^{G}}\right) \\
= & \left.\frac{\mathrm{MP}^{G}\left(x^{t+2}, y^{t+2}, c^{G}, p^{G}\right)-\mathrm{GIP}^{G}}{\mathrm{OP}^{G}\left(x^{t+2}, y^{t+2}\right)-\mathrm{GIP}^{G}}\right) \\
\times & \left(\frac{\mathrm{MP}^{G}\left(x^{t}, y^{t}, c^{G}, p^{G}\right)-\mathrm{GIP}^{G}}{\mathrm{OP}^{G}\left(x^{t}, y^{t}\right)-\mathrm{GIP}^{G}}\right)^{-1}=\mathrm{MP}_{t, t+2}^{G} .
\end{aligned}
$$

In other words, the global profit Malmquist change from period $t$ to $t+2$ is the product of the successive global profit Malmquist change from period $t$ to $t+1$ and from the period $t+1$ to $t+2$. Similarly, we can show that all of the components are circular.

The above properties show that in the presence of the negative data the $\mathrm{PM}^{G}$ index and its components are appropriate indices in the fact that they link in clear way productivity change indices over successive time periods.

\section{The Computation of the Proposed Index and Its Components}

This section prepares some DEA models to compute the $\mathrm{PM}^{G}$ index and its components. The observed profit $\mathrm{OP}^{G}\left(x^{t}, y^{t}\right)$ is computed as $\sum_{r=1}^{s} p_{r}^{G} y_{r k}^{t}-\sum_{i=1}^{m} c_{i}^{G} x_{i k}^{t}$. Similarly, the observed profits denoted by $\mathrm{OP}^{G}\left(x^{t+1}, y^{t+1}\right), \mathrm{OP}^{t}\left(x^{t}, y^{t}\right)$, and $\mathrm{OP}^{t+1}\left(x^{t+1}, y^{t+1}\right)$ are, respectively, $\sum_{r=1}^{s} p_{r}^{G} y_{r k}^{t+1}-\sum_{i=1}^{m} c_{i}^{G} x_{i k}^{t+1}$, $\sum_{r=1}^{s} p_{r}^{t} y_{r k}^{t}-\sum_{i=1}^{m} c_{i}^{t} x_{i k}^{t}$, and $\sum_{r=1}^{s} p_{r}^{t+1} y_{r k}^{t+1}-\sum_{i=1}^{m} c_{i}^{t+1} x_{i k}^{t+1}$.
We can compute $\operatorname{MP}^{t}\left(x^{t}, y^{t}, c^{t}, p^{t}\right)$ for unit $k$ by using the following model:

$$
\begin{aligned}
& \operatorname{MP}^{t}\left(x^{t}, y^{t}, c^{t}, p^{t}\right) \\
& =\max \quad \sum_{r=1}^{s} p_{r}^{t} y_{r}-\sum_{i=1}^{m} c_{i}^{t} x_{i} \\
& \text { s.t. } \quad y_{r}=\sum_{j=1}^{n} \lambda_{j} y_{r j}^{t} \geq y_{r k}^{t}, \quad r=1, \ldots, s, \\
& x_{i}=\sum_{j=1}^{n} \lambda_{j} x_{i j}^{t} \leq x_{i k}^{t}, \quad i=1, \ldots, m, \\
& \sum_{j=1}^{n} \lambda_{j}=1, \\
& \lambda_{j} \geq 0, \quad j=1, \ldots, n .
\end{aligned}
$$

Similarly, we will have

$$
\begin{array}{ll}
\mathrm{MP}^{G}\left(x^{t}, y^{t}, c^{G}, p^{G}\right) \\
=\max & \sum_{r=1}^{s} p_{r}^{G} y_{r}-\sum_{i=1}^{m} c_{i}^{G} x_{i} \\
\text { s.t. } \quad & y_{r}=\sum_{t=1}^{T} \sum_{j=1}^{n} \lambda_{j}^{t} y_{r j}^{t} \geq y_{r k}^{t}, \quad r=1, \ldots, s, \\
& x_{i}=\sum_{t=1}^{T} \sum_{j=1}^{n} \lambda_{j}^{t} x_{i j}^{t} \leq x_{i k}^{t}, \quad i=1, \ldots, m, \\
& \sum_{t=1}^{T} \sum_{j=1}^{n} \lambda_{j}^{t}=1, \\
& \lambda_{j}^{t} \geq 0, \quad j=1, \ldots, n, t=1, \ldots T, \\
\mathrm{MP}^{G}\left(x^{t+1}, y^{t+1}, c^{G}, p^{G}\right) \\
=\max \quad \sum_{r=1}^{s} p_{r}^{G} y_{r}-\sum_{i=1}^{m} c_{i}^{G} x_{i} \\
\quad y_{r}=\sum_{t=1}^{T} \sum_{j=1}^{n} \lambda_{j}^{t} y_{r j}^{t} \geq y_{r k}^{t+1}, \quad r=1, \ldots, s, \\
x_{i}=\sum_{t=1}^{T} \sum_{j=1}^{n} \lambda_{j}^{t} x_{i j}^{t} \leq x_{i k}^{t+1}, \quad i=1, \ldots, m, \\
\sum_{t=1}^{T} \sum_{j=1}^{n} \lambda_{j}^{t}=1, \\
\lambda_{j}^{t} \geq 0, \quad j=1, \ldots, n, t=1, \ldots T .
\end{array}
$$

The term $\mathrm{MP}^{t+1}\left(x^{t+1}, y^{t+1}, c^{t+1}, p^{t+1}\right)$ can be computed by using model (11) after replacing the time period $t$ with $t+1$. 
TABLE 1: Input, outputs, and their cost and prices for 3 successive periods.

\begin{tabular}{|c|c|c|c|c|c|c|c|c|c|c|c|c|c|c|c|c|c|c|}
\hline \multirow{2}{*}{ DMU } & \multicolumn{6}{|c|}{$t=1$} & \multicolumn{6}{|c|}{$t=2$} & \multicolumn{6}{|c|}{$t=3$} \\
\hline & $I$ & $c^{1}$ & $\mathrm{O} 1$ & $\mathrm{O} 2$ & $p_{1}^{1}$ & $p_{2}^{1}$ & $I$ & $c^{2}$ & O1 & $\mathrm{O} 2$ & $p_{1}^{2}$ & $p_{2}^{2}$ & $I$ & $c^{3}$ & $\mathrm{O} 1$ & $\mathrm{O} 2$ & $p_{1}^{3}$ & $p_{2}^{3}$ \\
\hline DMU1 & 3 & 2 & -2 & 1 & 1 & 3 & 4 & 2.3 & -1 & 2 & 1.1 & 3.2 & 6.5 & 3 & -1 & 3 & 1.4 & 4 \\
\hline DMU2 & 7 & 2 & -3 & 3 & 1 & 3 & 7 & 2.3 & -3 & 5 & 1.1 & 3.2 & 9 & 3 & -4 & 5 & 1.4 & 4 \\
\hline DMU3 & 2 & 2 & -4 & 3.5 & 1 & 3 & 4 & 2.3 & -5 & 6 & 1.1 & 3.2 & 3 & 3 & -4 & 7 & 1.4 & 4 \\
\hline DMU4 & 4 & 2 & -1 & 1 & 1 & 3 & 3 & 2.3 & -2 & 2 & 1.1 & 3.2 & 6 & 3 & -2 & 1 & 1.4 & 4 \\
\hline
\end{tabular}

TABLE 2: The results of the global profit Malmquist, profit efficiency change, and profit technical change.

\begin{tabular}{lccccccccc}
\hline DMU & \multicolumn{3}{c}{$\mathrm{PM}_{t, s}^{G}$} & & & $\mathrm{PEC}_{t, s}^{G}$ & & \multicolumn{2}{c}{$\mathrm{PTC}_{t, s}^{G}$} \\
& $\mathrm{PM}_{1,2}^{G}$ & $\mathrm{PM}_{2,3}^{G}$ & $\mathrm{PM}_{1,3}^{G}$ & $\mathrm{PEC}_{1,2}^{G}$ & $\mathrm{PEC}_{2,3}^{G}$ & $\mathrm{PEC}_{1,3}^{G}$ & $\mathrm{PTC}_{1,2}^{G}$ & $\mathrm{PTC}_{2,3}^{G}$ & $\mathrm{PTC}_{1,3}^{G}$ \\
\hline DMU1 & 1.1611 & 1 & 1.1611 & 1 & 1.1816 & 1.1816 & 1.1611 & 0.8463 \\
DMU2 & 1.3049 & 0.4695 & 0.6127 & 0.9999 & 0.2704 & 0.2704 & 1.3049 & 1.7366 & 2.2661 \\
DMU3 & 0.4978 & 2.009 & 1 & 0.9999 & 1.4038 & 1.4038 & 0.4978 & 1.431 & 0.7123 \\
DMU4 & 1.1555 & 0.5363 & 0.6197 & 0.9997 & 0.6657 & 0.6657 & 1.1555 & 0.8057 & 0.931 \\
\hline Avg. & 1.0298 & 1.0037 & 0.8484 & 0.9999 & 0.8804 & 0.8804 & 1.0298 & 1.2049 & 1.223 \\
\hline
\end{tabular}

For computing $\operatorname{RDM}^{t}\left(x_{k}^{t}, y_{k}^{t}, R_{x_{k}^{t}}^{\mathrm{GF}}, R_{y_{k}^{t}}^{\mathrm{GF}}\right)$ that is equal to $1-\beta_{k}^{*}$ we first calculate $\beta_{k}^{*}$ by using model (1) after replacing $R_{x_{i k}^{t}}$ and $R_{y_{r k}^{t}}$ with $R_{x_{i k}^{t}}^{\mathrm{GF}}$ and $R_{y_{r k}^{t}}^{\mathrm{GF}}$, respectively. Similarly, we can compute the value of $\mathrm{RDM}^{t+1}\left(x_{k}^{t+1}, y_{k}^{t+1}, R_{x_{k}^{t+1}}^{\mathrm{GF}}, R_{y_{k}^{t+1}}^{\mathrm{GF}}\right)$ after replacing the time period $t$ with $t+1$. In order to compute $\operatorname{RDM}^{G}\left(x_{k}^{t}, y_{k}^{t}, R_{x_{k}^{t}}^{\mathrm{GF}}, R_{y_{k}^{t}}^{\mathrm{GF}}\right)=1-\beta_{k}^{*}$, we first extend model (1) for the case that the production technology formed from all DMUs observed in all time periods $\left(T^{G}\right)$. The proposed model is shown in (13). In fact, the optimal value of model (13), $\beta_{k}^{*}$, is an inefficiency of $\mathrm{DMU}_{k}$ along direction $\left(g_{x}, g_{y}\right)=$ $\left(R_{x_{k}^{t}}^{\mathrm{GF}}, R_{y_{k}^{t}}^{\mathrm{GF}}\right)$ under the global production technology $T^{G}$ :

$$
\begin{aligned}
\beta_{k}^{*}=\max & \beta_{k} \\
\text { s.t. } \quad & \sum_{t=1}^{T} \sum_{j=1}^{n} \lambda_{j}^{t} x_{i j}^{t} \leq x_{i k}^{t}-\beta_{k} R_{x_{i k}^{t}}^{\mathrm{GF}}, \quad i=1, \ldots, m, \\
& \sum_{t=1}^{T} \sum_{j=1}^{n} \lambda_{j}^{t} y_{r j}^{t} \geq y_{r k}^{t}+\beta_{k} R_{y_{r k}^{t}}^{\mathrm{GF}}, \quad r=1, \ldots, s, \\
& \sum_{t=1}^{T} \sum_{j=1}^{n} \lambda_{j}^{t}=1, \\
& \lambda_{j}^{t} \geq 0, \quad j=1, \ldots, n, t=1, \ldots T .
\end{aligned}
$$

$\operatorname{RDM}^{G}\left(x_{k}^{t+1}, y_{k}^{t+1}, R_{x_{k}^{t+1}}^{\mathrm{GF}}, R_{y_{k}^{t+1}}^{\mathrm{GF}}\right)$ iscomputed using model (13) after replacing the time period $t$ with $t+1$.

By replacing the values obtained from the above models in the formulations of $\mathrm{PM}^{G}$ index and its components, the values of them can be computed. A value greater than 1 of $\mathrm{PM}^{G}$ index and its components indicates the regress and a value less than 1 implies the progress between periods $t$ and $t+1$. A value equal to 1 indicates that there is not any change between two time periods.

\section{Numerical Example}

This section illustrates the property of $\mathrm{PM}^{G}$ and its components, for example, the circularity property, using a numerical example. Table 1 shows units DMU1-DMU4 with one input (I) and two outputs (O1 and $\mathrm{O} 2)$ and their cost $\left(c^{t}\right)$ and prices $\left(p_{1}^{t}\right.$ and $\left.p_{2}^{t}\right)$ for 3 successive periods.

To compute the $\mathrm{PM}^{G}$ indices and their components by using the data in Table 1, suppose that the preferences about the input costs and output prices are available and have been specified by decision-makers as $\lambda_{j}=\mu_{j}=(1 / 3)(j=1,2,3)$. Therefore, the common costs and prices are obtained by using the decision-makers' preferences:

$$
\begin{gathered}
c^{G}=\frac{1}{3} c^{1}+\frac{1}{3} c^{2}+\frac{1}{3} c^{3}=2.4333 \\
p^{G}=\frac{1}{3} p^{1}+\frac{1}{3} p^{2}+\frac{1}{3} p^{3}=(1.6667,3.4)
\end{gathered}
$$

By using the data of periods 1,2, and 3, the inputs and the outputs of the global ideal point will be $2,-1$, and 7 , respectively.

Table 2 shows $\mathrm{PM}_{t, s}^{G}, \mathrm{PEC}_{t, s}^{G}$, and $\mathrm{TEC}_{t, s}^{G}$ of all of the DMUs for $t=1,2, s=2,3$, and $s \neq t$. For instance, the columns 2, 3, and 4 in Table 2 show $\mathrm{PM}_{1,2}^{G}, \mathrm{PM}_{2,3}^{G}$, and $\mathrm{PM}_{1,3}^{G}$, respectively. For DMU2, as an example, we have $\mathrm{PM}_{1,2}^{G}=1.3049>1$. That is, the productivity of DMU2 in period 2 is more than its productivity in period 1 and hence the productivity has been improved from the time period 1 to 2 .

According to $\mathrm{PM}_{2,3}^{G}=0.46951<1$, the productivity of DMU2 in period 3 is less than its productivity in period 2. By the circularity property of the profit Malmquist change, we can conclude that $\mathrm{PM}_{1,3}^{G}=\mathrm{PM}_{1,2}^{G} \times \mathrm{PM}_{2,3}^{G}=1.3049 \times 0.4695=$ 0.6127 .

Looking at the average values in Table 2, for example, we can see that the average global profit Malmquist index of all of the DMUs from the first period to the second period (1.0298) is higher than their average global profit Malmquist 
TABLE 3: The results of the RDM within-period-efficiency and allocative efficiency change.

\begin{tabular}{|c|c|c|c|c|c|c|}
\hline \multirow{2}{*}{ DMU } & \multicolumn{3}{|c|}{$\mathrm{REC}_{t, s}^{G}$} & \multicolumn{3}{|c|}{$\mathrm{AEC}_{t, s}^{G}$} \\
\hline & $\operatorname{REC}_{1,2}^{G}$ & $\mathrm{REC}_{2,3}^{G}$ & $\operatorname{REC}_{1,3}^{G}$ & $\mathrm{AEC}_{1,2}^{G}$ & $\mathrm{AEC}_{2,3}^{G}$ & $\mathrm{AEC}_{1,3}^{G}$ \\
\hline DMU1 & 2.1333 & 1.5 & 3.2 & 0.4688 & 0.7878 & 0.3693 \\
\hline DMU2 & 0.9821 & 0.4156 & 0.4082 & 1.0182 & 0.6506 & 0.6624 \\
\hline DMU3 & 1.75 & 2 & 3.5 & 0.5714 & 0.7019 & 0.4011 \\
\hline DMU4 & 1.3333 & 0.25 & 0.3333 & 0.75 & 2.6627 & 1.997 \\
\hline Avg. & 1.5497 & 1.0414 & 1.8604 & 0.7021 & 1.2007 & 0.8574 \\
\hline
\end{tabular}

TABLE 4: The results of the frontier shift between the VRS frontiers and price effect.

\begin{tabular}{|c|c|c|c|c|c|c|}
\hline DMU & $\mathrm{TC}_{1,2}^{G}$ & $\begin{array}{l}\mathrm{TC}_{t, s}^{G} \\
\mathrm{TC}_{2,3}^{G}\end{array}$ & $\mathrm{TC}_{1,3}^{G}$ & $\mathrm{PE}_{1,2}^{G}$ & $\begin{array}{l}\mathrm{PE}_{t, s}^{G} \\
\mathrm{PE}_{2,3}^{G}\end{array}$ & $\mathrm{PE}_{1,3}^{G}$ \\
\hline DMU1 & 0.6064 & 0.5063 & 0.307 & 1.9147 & 1.6715 & 3.2004 \\
\hline DMU2 & 1.4915 & 1.5912 & 2.3733 & 0.8749 & 1.0914 & 0.9549 \\
\hline DMU3 & 0.45 & 0.8254 & 0.3714 & 1.1062 & 1.7338 & 1.9178 \\
\hline DMU4 & 0.9 & 1.6234 & 1.461 & 1.2839 & 0.4963 & 0.6372 \\
\hline Avg. & 0.862 & 1.1366 & 1.1282 & 1.2949 & 1.2483 & 1.6776 \\
\hline
\end{tabular}

index from the second period to the third period (1.0037). The average of columns 2, 3, and 4 in Table 2 shows that the average growth of all of the DMUs from the first period to the third period is less than their growth from period 1 to period 2 and that from period 2 to period 3. A similar discussion can be made for the other columns of Table 2 .

Tables 3 and 4 illustrate the results from the RDM withinperiod-efficiency change, allocative efficiency change, the frontier shift between the VRS frontiers, and residual price change from different periods to the periods 2 and 3 , and the averages are shown in the last row of these tables.

For example, the frontier shift between the VRS frontiers along the ray $\left(x_{1}^{2}, y_{1}^{2}\right)$ from period 1 to period 2 is 0.6064 ; that is, there is a decrease in technical progress for DMU1 from period 1 to period 2 .

Using the average values in Table 4, for example, we can see that the average frontier shifts between the VRS frontiers along the rays $\left(x_{1}^{2}, y_{1}^{2}\right),\left(x_{2}^{2}, y_{2}^{2}\right),\left(x_{3}^{2}, y_{3}^{2}\right)$, and $\left(x_{4}^{2}, y_{4}^{2}\right)$ of all of the DMUs from the first period to the second period (0.862) are less than their average frontier shifts between the VRS frontiers along the rays $\left(x_{1}^{3}, y_{1}^{3}\right),\left(x_{2}^{3}, y_{2}^{3}\right),\left(x_{3}^{3}, y_{3}^{3}\right)$, and $\left(x_{4}^{3}, y_{4}^{3}\right)$ from the second period to the third period (1.1366). The value $\mathrm{PE}_{1,2}^{G}=0.8749<1$, for DMU2 as an example, for the $\mathrm{PE}^{G}$ component, indicates that the effect of input cost changes from the first period to the second period is detrimental to productivity.

\section{Conclusions}

Under the VRS assumption allocative and profit efficiencies have been defined for the case that the dataset contains the inputs and/or outputs with the negative values in data envelopment analysis. The definitions could be generalized when the unit cost of the ith input $(i=1, \ldots, m)$ or the unit price of the $r$ th output $(r=1, \ldots, s)$ of all of DMUs is different. The proposed $\mathrm{PM}^{G}$ index decomposed into some components in two stages. The RDM and the defined efficiencies were used to compute the proposed index and its components. The interpretations of the components were presented. A numerical example has been presented for three successive periods of time to illustrate the properties of $\mathrm{PM}^{G}$ and its components in the presence of the negative inputs and outputs.

\section{Conflict of Interests}

The authors declare that there is no conflict of interests regarding the publication of this paper.

\section{Acknowledgment}

Financial support of this research, in a project entitled An Overall Index to Determine the Progress or Regress of the Productivity of DMUs and Its Global Form in the Presence of the Negative Data, Islamic Azad University, Central Tehran Branch, is acknowledged.

\section{References}

[1] D. W. Caves, L. R. Christensen, and W. E. Diewert, "The economic theory of index numbers and the measurement of input, output and productivity," Econometrica, vol. 50, pp. 1393$1414,1982$.

[2] R. Fare, S. Grosskopf, M. Norris, and Z. Zhang, "Productivity growth, technical progress, and efficiency change in industrialized countries," American Economic Review, vol. 84, no. 1, pp. 66-83, 1994.

[3] R. Färe, S. Grosskopf, B. Lindgren, and P. Roos, "Productivity developments in Swedish hospitals: a Malmquist output index approach," in Data Envelopment Analysis: Theory, Methodology and Applications, A. Charnes, W. W. Cooper, A. Lewin, and L. Seiford, Eds., pp. 253-272, Kluwer Academic Publishers, 1994. 
[4] A. Q. Nyrud and S. Baardsen, "Production efficiency and productivity growth in Norwegian sawmilling," Forest Science, vol. 49, no. 1, pp. 89-97, 2003.

[5] J. T. Pastor and C. A. K. Lovell, "A global Malmquist productivity index," Economics Letters, vol. 88, no. 2, pp. 266-271, 2005.

[6] M. Portela and E. Thanassoulis, "A circular Malmquist-type index for measuring productivity," Aston Working Paper RP0802, Aston University, Birmingham, UK, 2008.

[7] F. Hosseinzadeh Lotfi, G. Jahanshahloo, M. Vaez-Ghasemi, and Z. Moghaddas, "Modified Malmquist productivity index based on present time value of money," Journal of Applied Mathematics, vol. 2013, Article ID 607190, 8 pages, 2013.

[8] F. H. Lotfi, G. R. Jahanshahloo, M. Vaez-Ghasemi, and Z. Moghaddas, "Evaluation progress and regress of balanced scorecards by multi-stage malmquist productivity index," Journal of Industrial and Production Engineering, vol. 30, no. 5, 2013.

[9] N. Maniadakis and E. Thanassoulis, "A cost Malmquist productivity index," European Journal of Operational Research, vol. 154, no. 2, pp. 396-409, 2004.

[10] G. Tohidi, S. Razavyan, and S. Tohidnia, "A profit Malmquist productivity index," Journal of Industrial Engineering International, vol. 6, pp. 23-30, 2008.

[11] G. Tohidi and S. Razavyan, "A circular global profit Malmquist productivity index in data envelopment analysis," Applied Mathematical Modelling, vol. 37, no. 1-2, pp. 216-227, 2013.

[12] G. Tohidi, S. Razavyan, and S. Tohidnia, "A global cost Malmquist productivity index using data envelopment analysis," Journal of the Operational Research Society, vol. 63, no. 1, pp. 72-78, 2012.

[13] W. W. Cooper, L. M. Seiford, and K. Tone, Data Envelopment Analysis: A Comprehensive Text with Models, Applications, References and DEA-Solver Software, Springer, New York, NY, USA, 2nd edition, 2007.

[14] J. T. Pastor and J. L. Ruiz, "Variables with negative values in DEA," in Modeling Data Irregularities and Structural Complexities in Data Envelopment Analysis, J. Zhu and W. D. Cook, Eds., Springer, Berlin, Germany, 2007.

[15] M. C. A. S. Portela, E. Thanassoulis, and G. Simpson, "Negative data in DEA: a directional distance approach applied to bank branches," Journal of the Operational Research Society, vol. 55, no. 10, pp. 1111-1121, 2004.

[16] M. C. A. S. Portela and E. Thanassoulis, "Malmquist-type indices in the presence of negative data: an application to bank branches," Journal of Banking and Finance, vol. 34, no. 7, pp. 1472-1483, 2010.

[17] A. Emrouznejad, A. L. Anouze, and E. Thanassoulis, "A semioriented radial measure for measuring the efficiency of decision making units with negative data, using DEA," European Journal of Operational Research, vol. 200, no. 1, pp. 297-304, 2010.

[18] J. A. Sharp, W. Meng, and W. Liu, "A modified slacks-based measure model for data envelopment analysis with "natural" negative outputs and inputs," Journal of the Operational Research Society, vol. 58, no. 12, pp. 1672-1677, 2007. 


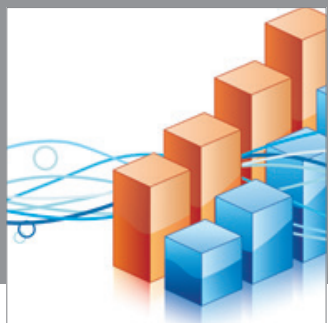

Advances in

Operations Research

mansans

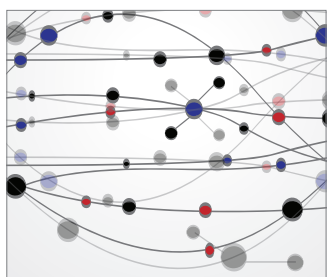

The Scientific World Journal
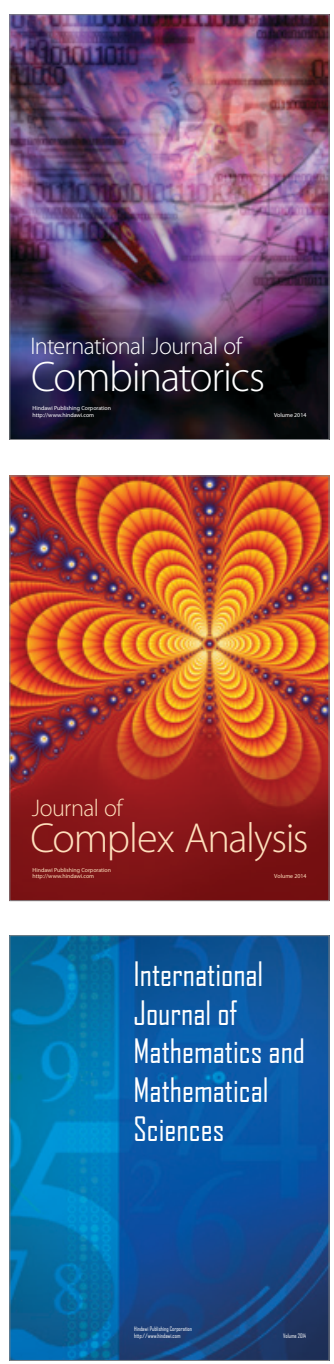
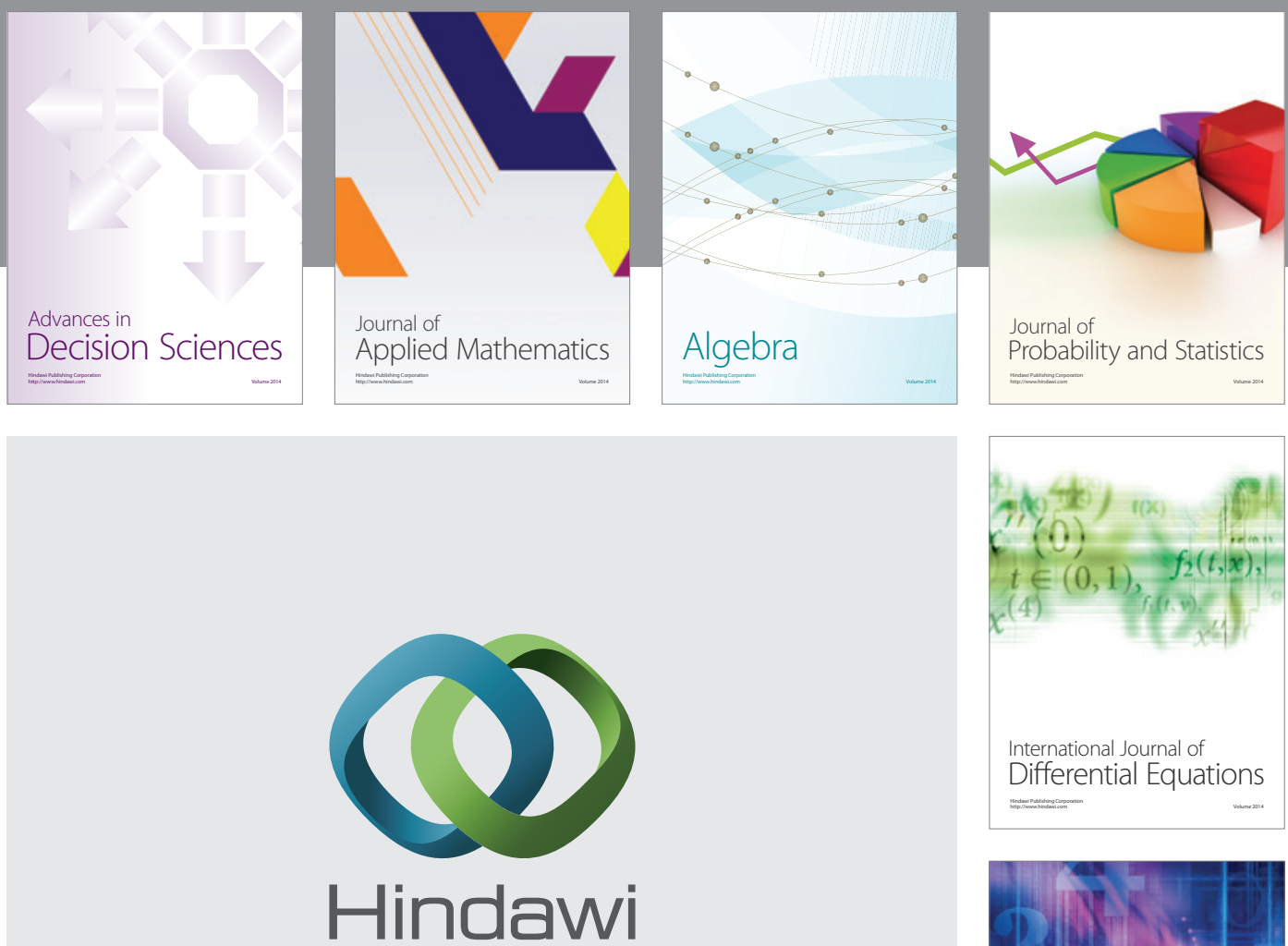

Submit your manuscripts at http://www.hindawi.com
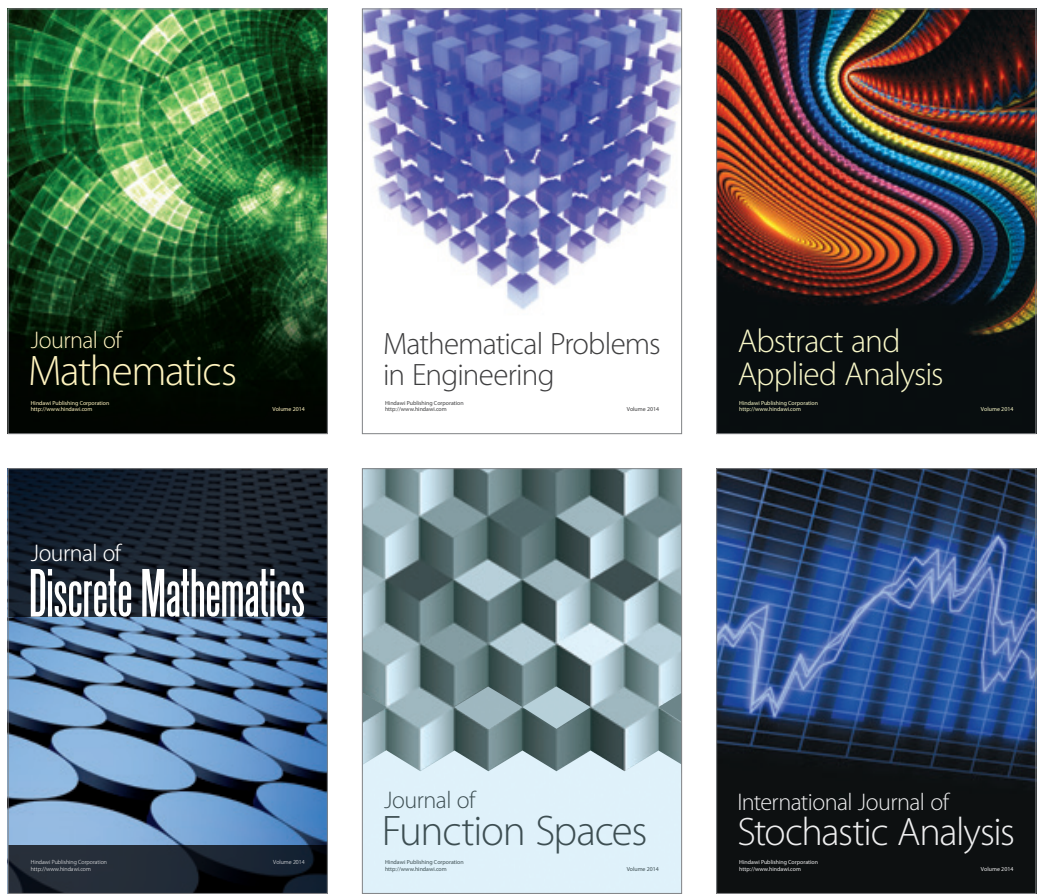

Journal of

Function Spaces

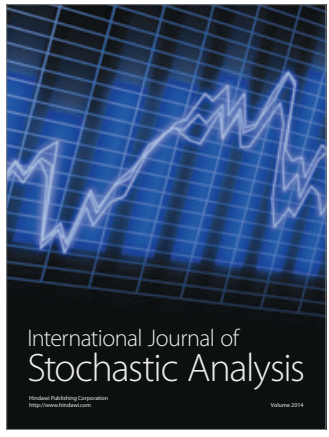

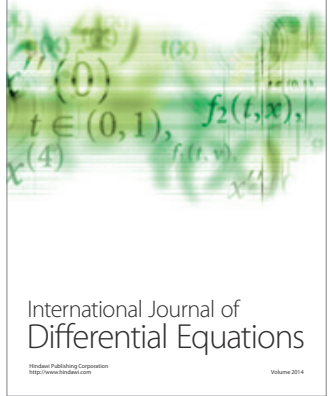
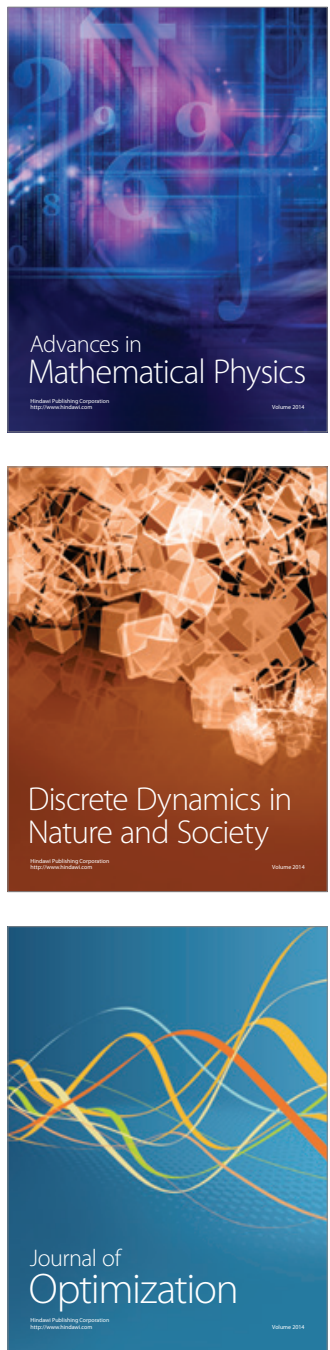